\title{
Averaging processes in ratings and choices based on numerical information
}

\author{
IRWIN P. LEVIN* \\ University of Iowa, Iowa City, lowa 52242
}

\begin{abstract}
Ss were presented sets of numbers said to represent sample price information from grocery stores. Ss rated the relative desirability of shopping at each of a series of stores and were also asked to make paired-comparison preference choices. In Experiment I, some sets contained favorable information, some contained unfavorable information, and some contained neutral information added to the favorable or unfavorable information. The addition of neutral information led to a decrease in the polarity of responses. This is consistent with an averaging, but not an adding, formulation of how the information is integrated. In Experiment II, sets of favorable or unfavorable information varied in size and a set-size effect was obtained. The greater the amount of favorable or unfavorable information, the more extreme the response. This was accounted for by assuming that an initial neutral expectancy is averaged with the information presented.
\end{abstract}

Anderson's (1974) theory of information integration has been used to test algebraic models describing now information judgments of varying kinds have been represented by averaging processes. For example, Anderson (1973) showed that an averaging model could describe judged statesmanship of U.S. Presidents based on information contained in descriptive paragraphs; Anderson, Lindner, and Lopes (1973) showed that judgments of group attractiveness could be described as an average of the attractiveness of individual members. Birnbaum (1972) showed that morality judgments based on combinations of objectionable behaviors were related to the average value of the component behaviors; and Levin (1974a) indicated that people combine their own and others' opinions through an averaging process.

The present paper describes two experiments in which comparative ratings and choices of stores are based on combinations of numerical price information. In order to demonstrate that averaging processes describe how such ratings and choices are made, Experiment I provides a critical comparative test of the competing notions that people integrate such information by adding or that they integrate the information by averaging. The test involves the addition of neutral information to favorable or unfavorable information. According to an adding model, the addition of neutral information should not affect the response. According to an averaging model, the addition of neutral information should neutralize the response.

Experiment II further delineates the averaging process by examining the "set-size" effect. The set-size effect refers to the finding that an increase in the number of equal-valued (nonneutral) information items leads to a

*This work was supported by U.S. Public Health Service Grant MH 23911-01. The author wishes to thank Charles Gibbs, Valerie Hensley, and Jeanette Dolezal for their assistance. more extreme response. This effect has often been demonstrated in impression formation (Anderson, 1967; Levin \& Kaplan, 1974; Sloan \& Ostrom, 1974). The set-size effect has been explained by assuming that an initial neutral expectancy is averaged with the information presented. Specifically, an averaging model incorporating an initial expectancy or response disposition takes the following form:

$$
\mathrm{R}=\left(\mathrm{w}_{\mathrm{o}} \mathrm{A}_{\mathrm{o}}+\mathrm{kwA}\right) /\left(\mathrm{w}_{\mathrm{o}}+\mathrm{kw}\right)
$$

where there are $\mathrm{k}$ informational stimuli of value $\mathrm{A}$ and weight $\mathrm{w}$ and where the initial expectancy has scale value $A_{o}$ on the dimension of judgment and weight $w_{0}$. This formulation describes a negatively accelerated growth function as $\mathrm{k}$ increases, with asymptote $\mathrm{A}$. Support for this formulation in impression formation has been provided by Anderson (1967). The current Experiment II extends support of the model to ratings and choices of stores based on numerical price information.

\section{EXPERIMENT I}

Experiment I was designed to provide a qualitative test of averaging vs adding in describing how numerical information is combined to determine affective ratings. The logic behind the test is simple: the addition of neutral-valued information to sets of favorable or unfavorable information should have little or no effect if an adding process holds but should decrease the polarity of rating responses if an averaging process holds. Such tests have been performed before (e.g., Anderson, 1973), but not with numerical information.

Samples of percentage food price increases for a series of hypothetical grocery stores were presented. In Part 1 , a sample of percentage price increase information was presented for a different store on each trial, and $S$ rated 
how much he would like to shop at that store in relation to the other stores. In Part 2, a pair of samples representing percentage price increases in two different stores was presented on each trial, and $S$ was asked to choose the one store in a pair where he would prefer to shop. Included were favorable (F) samples where the mean percentage price increase was low, unfavorable (U) samples where the mean percentage price increase was high, samples formed by combining favorable and neutral $(F+N)$ values, and samples formed by combining unfavorable and neutral $(U+N)$ values. Of interest in Part 1 were comparisons between responses to $\mathrm{F}$ samples and $\mathrm{F}+\mathrm{N}$ samples and comparisons between responses to $\mathrm{U}$ samples and $\mathrm{U}+\mathrm{N}$ samples. In Part 2, preferences between $\mathrm{F}$ and $\mathrm{F}+\mathrm{N}$ samples and preferences between $\mathrm{U}$ and $\mathrm{U}+\mathrm{N}$ samples could be assessed directly because they were paired with each other on single trials.

\section{Method}

Nineteen volunteers from a dormitory at the University of lowa were tested in a single group session. In Part 1, each S was shown a series of sets of numbers. Each number within a set was said to represent the percentage price increase over the past 2 years for a randomly selected food item from a grocery store. Each set was said to represent a sample from a different store. Ss were told that different items were chosen for different stores and that the number of items chosen differed between stores.

Twenty-one sets were presented, including two of each of the following sets of theoretical interest: $F_{4}$, a set of 4 numbers with mean 20 (representing a favorable mean level of percentage price increases); $F_{8}$, a set of 8 numbers with mean $20 ; U_{4}$, a set of 4 numbers with mean 80 (representing an unfavorable mean level of percentage price increases); $\mathrm{U}_{8}$, a set of 8 numbers with mean $80 ; \mathrm{F}_{4}+\mathrm{N}_{4}$, a set of 8 numbers composed of a subset of 4 numbers with mean 20 randomly interspersed with a subset of 4 numbers with mean 50 (representing a relatively neutral mean level); $F_{8}+N_{8}$, a set of 16 numbers composed of a subset of 8 numbers with mean 20 combined with a subset of 8 numbers with mean $50 ; \mathrm{U}_{4}+\mathrm{N}_{4}$, a set of 8 numbers composed of a subset of 4 numbers with mean 80 and a subset of 4 numbers with mean $50 ; \mathrm{U}_{8}+\mathrm{N}_{8}$, a set of 16 numbers composed of a subset of 8 numbers with mean 80 and a subset of 8 numbers with mean 50 . Samples of the specified sizes were chosen from a table of random numbers and adjusted for mean value.

The 21 sets were printed in random order in a test booklet. The Ss were instructed to rate on a 20 -point scale how much they would like to shop at each store in relation to the other stores. In order to ensure relative ratings, Ss were given $2 \mathrm{~min}$ to inspect all the samples before starting to rate them. The $\mathrm{E}$ signaled when $S$ could begin rating and also signaled the rating of each successive set. For each set, a 10 -sec period was allotted for examining the numbers and an additional $10 \mathrm{sec}$ for responding. The $\mathrm{S}$ marked his response to a given set in a blank space provided in the test booklet. He was told that the more favorably he rates a particular store and the greater the desirability of shopping at that store in comparison to others, the closer to 20 should be the number he uses. The more unfavorably he rates a particular store, the closer to 1 should be the number he uses.

In line with previous work on intuitive statistical estimates (e.g., Levin, 1974b), instructions stressed that $S$ should not try to make precise arithmetic calculations. (In fact, there was insufficient time to do so.) Rather, $\mathrm{S}$ was told to indicate his impression of each store.
Table 1

Tests of Averaging vs Adding in Experiment I

\begin{tabular}{ccccc} 
& Mean & \multicolumn{3}{c}{ Mean } \\
Set & Response & Set & Response & $\mathfrak{t}(18)$ \\
\hline
\end{tabular}

Part I: Rating Responses

\begin{tabular}{lrrrl}
$\mathrm{F}_{4}$ & 15.46 & $\mathrm{~F}_{4}+\mathrm{N}_{4}$ & 11.76 & $6.22^{* *}$ \\
$\mathrm{~F}_{8}$ & 16.74 & $\mathrm{~F}_{8}+\mathrm{N}_{8}$ & 12.29 & $7.01 * *$ \\
$\mathrm{U}_{4}$ & 5.68 & $\mathrm{U}_{4}+\mathrm{N}_{4}$ & 7.37 & $2.22 *$ \\
$\mathrm{U}_{8}$ & 4.66 & $\mathrm{U}_{8}+\mathrm{N}_{8}$ & 7.97 & $4.68 *$ \\
\hline
\end{tabular}

\begin{tabular}{|c|c|c|}
\hline 4.66 & $\mathrm{U}_{8}+\mathrm{N}_{8}$ & $4.68 * *$ \\
\hline Paired Sets & $\begin{array}{c}\text { Mean } \\
\text { Response }\end{array}$ & $t(18)$ \\
\hline
\end{tabular}

Part 2: Preference Responses

\begin{tabular}{lll}
$\mathrm{F}_{4}$ vs $\mathrm{F}_{4}+\mathrm{N}_{4}$ & 4.53 & $7.37^{* *}$ \\
$\mathrm{~F}_{8}$ vs $\mathrm{F}_{8}+\mathrm{N}_{8}$ & 5.29 & $9.29^{* *}$ \\
$\mathrm{U}_{4}$ vs $\mathrm{U}_{4}+\mathrm{N}_{4}$ & 2.89 & $3.33^{* *}$ \\
$\mathrm{U}_{8}$ vs $\mathrm{U}_{8}+\mathrm{N}_{8}$ & 3.37 & $7.81^{* *}$ \\
\hline${ }^{*} p<.05 \quad{ }^{* *} p<.01$ &
\end{tabular}

After completing Part 1, Ss were told to turn to the second part of their booklets. Here, pairs of samples representing percentage price increases in two different stores were presented. On each trial of Part 2, S was required to choose the one store in a pair where he would most prefer to shop and to indicate how much he would prefer that store over the other. The 13 pairs of samples presented included two of each of thefollowing pairings of theoretical interest: $F_{4}$ vs $F_{4}+N_{4}, F_{8}$ vs $F_{8}+N_{8}, U_{4}$ vs $U_{4}$ $+\mathrm{N}_{4}$, and $\mathrm{U}_{8}$ vs $\mathrm{U}_{8}+\mathrm{N}_{8}$.

Ss were given $15 \mathrm{sec}$ to examine the information in a given pair and an additional $10 \mathrm{sec}$ to respond. The sample printed on the left side of the page was designated as Sample $A$ and the sample printed on the right side was designated as Sample B. Left-right position was counterbalanced across the two examples of a given type of pair. The $S$ was told to print the letter A or B corresponding to his preference choice within a pair and to print a number between 1 and 10 to indicate how much he preferred that store over the other.

\section{Results and Discussion}

The mean rating responses on a 20-point scale for Part 1 of Experiment I are given in the upper part of Table 1. It can be seen that the addition of a set of value $\mathrm{N}$ tended to decrease the response to $\mathrm{F}$ sets and increase the response to $U$ sets. The $t$ tests summarized in the right-hand column compare the mean responses within each row. Each comparison is statistically significant and supports an averaging formulation.

Preference responses for the paired comparisons of Part 2 are summarized in the bottom part of Table 1. Preference responses were scored as positive if they were consistent with an averaging formulation-i.e., $F$ chosen over $\mathrm{F}+\mathrm{N}, \mathrm{U}+\mathrm{N}$ chosen over $\mathrm{U}-$ and negative otherwise. Only $7 \%$ of the individual choices were inconsistent with averaging. The $t$ tests summarized in the right-hand column show that the mean preference response was significantly greater than zero for each type of pair.

Taken together, the results of Parts 1 and 2 of Experiment I provide strong support for the proposition that Ss average rather than add the values of the price increase information items when comparing stores. 
Table 2

Mean Rating Responses for Part 1 of Experiment Il

\begin{tabular}{|c|c|c|c|c|c|c|c|c|c|c|c|}
\hline \multirow{2}{*}{$\begin{array}{l}\text { Set } \\
\text { Size }\end{array}$} & \multicolumn{2}{|c|}{30} & \multicolumn{2}{|c|}{40} & \multicolumn{2}{|c|}{$\begin{array}{c}\text { Sample Mean } \\
50 \\
\end{array}$} & \multicolumn{2}{|c|}{60} & \multicolumn{2}{|c|}{70} & \\
\hline & Mean & SE & Mean & SE & Mean & SE & Mean & $\mathrm{SE}$ & Mean & $\mathrm{SE}$ & \\
\hline 4 & 14.95 & 3.02 & 13.15 & 3.23 & 9.65 & 3.30 & 8.75 & 3.42 & 5.98 & 3.42 & 10.50 \\
\hline 8 & 15.98 & 3.04 & 13.50 & 3.76 & 10.75 & 3.44 & 8.50 & 3.11 & 5.55 & 3.14 & 10.86 \\
\hline 16 & 16.28 & 3.47 & 13.72 & 2.79 & 10.37 & 3.27 & 8.58 & 3.75 & 5.13 & 2.99 & 10.82 \\
\hline \multirow[t]{2}{*}{32} & 16.38 & 3.68 & 12.52 & 3.66 & 10.57 & 4.64 & 7.57 & 3.26 & 4.00 & 3.54 & 10.21 \\
\hline & 15.90 & & 13.22 & & 10.34 & & 8.35 & & 5.17 & & \\
\hline
\end{tabular}

Note $-S E=$ standard error of the mean.

Experiment II further examined the nature of the averaging process.

\section{EXPERIMENT II}

Experiment II investigated the set-size effect with numerical information. Samples of food price information for hypothetical grocery stores were again presented. The size of the sample and the mean value of the numbers in the sample were varied. In Part 1 where S made comparative ratings of stores based on single samples, set-size effects would show up as increases in response polarity as the amount of favorable or unfavorable information increased. In Part 2 where paired-comparison preferences were required, pairs were included where sample mean was the same but sample size differed between the two members of the pair. A positive set-size effect would be demonstrated if Ss reliably chose the larger sample when sample mean was low (favorable information) and chose the smaller sample when sample mean was high (unfavorable information). Such set-size effects could be explained by assuming that a relatively neutral initial expectancy is averaged with the favorable or unfavorable information.

\section{Method}

The basic procedures for Parts 1 and 2 of Experiment II were the same as those for Experiment I. The main difference was in the composition of the stimulus sets. Another difference was the greater number of Ss employed in Experiment II. More Ss were required because the set-size effect was expected to be more subtle than averaging vs adding differences. (A small set-size effect can be observed in Part 1 of Experiment $I$ by comparing responses for $F_{4}$ and $F_{8}$ and responses for $U_{4}$ and $U_{8}$.

Sixty-eight students from introductory psychology classes at the University of Iowa were tested in groups ranging in size from 4 to 10 . Twenty samples of percentage price increase scores were presented in Part 1. Sample mean and set size were varied factorially in a $5 \times 4$ within-S design, with mean values of 30,40 , 50,60 , and 70 and set sizes of $4,8,16$, and 32 . Included in the paired comparisons of Part 2 were pairs in which both sample means equalled 30 or both equalled 70 , but the size of the two samples within a pair differed. The following six set-size pairings were used: $4-8,4-16,4-32,8-16,8-32,16-32$. In addition to the 12 pairs formed by combining these set-size pairings with sample mean values of 30 and 70,8 filler pairs were included where the value of the sample means differed within a pair. Two different random orderings of the pairs were formed, with half of the Ss receiving each order. Because of the use of larger samples in
Experiment II than in Experiment I, Ss were given somewhat longer to examine each sample-15 sec per sample in Part 1 and $30 \mathrm{sec}$ per pair in Part 2.

\section{Results and Discussion}

The mean rating response (on a scale of 1 to 20) for each combination of sample mean and set size in Part 1 is shown in Table 2 for the $60 \mathrm{Ss}$ included in the statistical analysis of the data. ${ }^{1}$ It can be seen that as the mean percentage price increase increased, the mean rating response decreased. In analysis of variance, sample mean was a highly significant source of variance, $F(4,236)=369.66$. Trend analyses of the column means revealed that the linear component was highly significant, while departures from linearity were nonsignificant. A linear relationship between sample mean values and subjective ratings is consistent with other unpublished data from the writer's laboratory.

Set size was not a significant source of variance, $F(3,177)=1.97, p>.10$, but the interaction of Set Size by Sample Mean was significant, $F(12,708)=2.60$, $\mathrm{p}<.01$. The form of the interaction is consistent with theoretical predictions of the set-size effect. Set-size effects should be reflected in an increase in mean rating response as set size increases for low values of sample mean (e.g., 30, representing the most favorable mean level of price increase) and a decrease in mean rating response as set size increases for high values of sample mean (e.g., 70, representing the most unfavorable mean level of price increase). It can be seen in Table 2 that differences in mean rating response as a function of set size were in the predicted direction for Sample Means 30 and 70 . Trend tests over set sizes were computed for each value of sample mean, with particular interest in the linear trends for Sample Means 30 and 70 . The linear trend was significant in each of these two cases and also for Sample Mean 60. Higher-order trends were not significant for each of these mean values.

Responses for Part 2 paired comparisons were compiled as follows: if $S$ chose the sample in the pair with the larger set size, his preference rating was assigned a plus sign; if $S$ chose the sample with the smaller set size, his preference rating was assigned a minus sign. Thus individual responses could range from -10 to +10 . Mean response values for pairs in which the two sample 
Table 3

Mean Preference Responses for Part 2 of Experiment II

\begin{tabular}{|c|c|c|c|c|c|c|c|c|c|c|c|c|c|c|}
\hline & & \multicolumn{2}{|c|}{$4-8$} & \multicolumn{2}{|c|}{$4-16$} & \multicolumn{2}{|c|}{$\begin{array}{l}\text { Set Size } \\
4-32\end{array}$} & \multicolumn{2}{|c|}{$\begin{array}{c}\text { Combination } \\
8-16\end{array}$} & \multicolumn{2}{|c|}{$8-32$} & \multicolumn{2}{|c|}{$16-32$} & \multirow[b]{2}{*}{ Mean } \\
\hline & & Mean & SE & Mean & $\mathrm{SE}$ & Mean & $\mathrm{SE}$ & Mean & $\mathrm{SE}$ & Mean & SE & Mean & $\mathrm{SE}$ & \\
\hline Sample & 30 & +.02 & .52 & +.70 & .56 & +.93 & .63 & -.40 & .63 & +1.03 & .58 & +2.07 & .48 & +.72 \\
\hline Mean & 70 & -1.20 & .50 & -1.22 & .40 & -3.03 & .44 & -1.58 & .33 & -1.65 & .48 & -1.13 & .33 & -1.64 \\
\hline
\end{tabular}

Note $-S E=$ standard error of the mean.

means were equal but set size differed are shown in Table 3.

It can be seen that, with one exception, the means are positive for Sample Mean 30 and negative for Sample Mean 70. Averaged over set-size combinations, the mean response was significantly greater than zero for Sample Mean 30, $\mathrm{t}(59)=2.21, \mathrm{p}<.05$, and the mean response was significantly less than zero for Sample Mean 70 , $t(59)=6.83, p<.01$. These results are consistent with the notion that increases in set size lead to an increase in response polarity. In the case of relatively favorable stimulus values, as represented here by Sample Mean 30 , this means that the larger set is evaluated as being more favorable than the smaller set and is consequently preferred over the smaller set. In the case of relatively unfavorable stimulus values, as represented by Sample Mean 70 , this means that the larger set is evaluated as being more unfavorable than the smaller set and thus the smaller set is preferred.

The asymmetry between the magnitude of the set-size effect for Sample Means 30 and 70 might be caused by a bias toward choosing the smaller sample in a pair due to the fact that it is easier to assimilate the information in a smaller set. Such bias would work in the same direction as the set-size effect for Sample Mean 70, but it would work against the set-size effect for Sample Mean 30. Nevertheless, the set-size effect was significant in both cases. An alternative explanation of the asymmetry is provided by Eq. 1. The initial expectancy, $A_{0}$, may be closer to Sample Mean 30 than to Sample Mean 70. The asymptotic level of the set-size growth function for Sample Mean 70 would then be farther from $A_{o}$ than would the corresponding level for Sample Mean 30, and increases in set size would have a greater effect for Sample Mean 70.

When Eq. 1 is extended to preference responses in the paired-comparisons choice paradigm, degree of preference should depend in part on the difference in set size $\left(\mathrm{N}_{1}-\mathrm{N}_{2}\right)$ between the two samples in a pair. Specifically, for a given value of $\mathrm{N}_{1}$ or $\mathrm{N}_{2}$, degree of preference should increase as $\left(\mathrm{N}_{1}-\mathrm{N}_{2}\right)$ increases (see Levin, Schmidt, \& Norman, 1971, for the appropriate derivation). It can be seen by inspecting the absolute numerical values in Table 3 that this was generally the case, although there were some exceptions.

In summary, there is ample evidence that affective ratings and choices based on varying amounts of numerical information are affected by the amount of information presented. Ratings increase or decrease appropriately with set size for favorable and unfavorable levels of information value. Choices of the larger set within a pair tend to occur for favorable information values and choices of the smaller set tend to occur for unfavorable information values. Degree of preference within a pair of sets varies as a function of the difference in set size,

\section{OVERALL DISCUSSION}

Experiment I showed that the addition of neutral-valued subsets of price information to favorable or unfavorable subsets served to neutralize the rating responses. This set of findings is consistent with an averaging but not an adding formulation. It appears that information within a set is combined by an averaging rather than an adding process in determining affective ratings. Experiment II showed that an increase in the number of favorable or unfavorable pieces of price information increased the polarity of the rating associated with that set of information. This is consistent with the set-size effect typically obtained in studies of impression formation and can be explained by assuming that an initial expectancy is averaged with the information presented. The results of Experiment II extend the generality of the set-size effect. An interesting empirical question is whether or not the following simple principle of information usage can be established for a variety of tasks requiring relative affective judgments: the greater the amount of (nonneutral) information, the more extreme the response.

The present concern with affective responses based on the integration of numerical information represents a natural extension of two previous lines of research. A number of investigators have been interested in man as an "intuitive statistician" (Peterson \& Beach, 1967) and have studied how-or, more precisely, how accurately-statistical properties of sets of numbers are estimated at the subjective or intuitive level. For example, number-averaging behavior has been studied by Spencer $(1961,1963)$, who examined "error of judgment" as a function of distributional characteristics of samples of numbers. Spencer's concern with accuracy is characteristic of the investigations of intuitive statistical processes and precludes the examination of rating responses which have no physical yardstick. On 
the other hand, rating responses have been used extensively in research dealing with the integration of qualitative stimuli such as person descriptions (Anderson, 1974). The present study provided a preliminary examination of how statistical properties of sets of numbers affect ratings and preference responses in a task related to consumer information processing. A more extensive series of experiments currently underway is aimed at describing how numerical information is perceived and integrated in a variety of judgmental and decision-making tasks.

\section{REFERENCES}

Anderson, N. H. Averaging model analysis of set size effect in impression formation. Journal of Experimental Psychology, $1967,75,158-165$.

Anderson, N. H. Integration theory applied to attitudes about U.S. Presidents. Journal of Educational Psychology, 1973, 64, 1-8.

Anderson, N. H. Information integration theory: A brief survey. In D. H. Krantz, R. C. Atkinson, R. D. Luce, and P. Suppes (Eds.), Contemporary developments in mathematical psychology. Vol. 2. San Francisco, Freeman, 1974.

Anderson, N. H., Lindner, R., \& Lopes, L. L. Integration theory applied to judgments of groups. Journal of Personality \& Social Psychology, 1973, 26, 400-408.

Birnbaum, M. H. Morality judgments: Tests of an averaging model. Journal of Experimental Psychology, 1972, 93, 35-42.

Levin, I. P. Combining personal and others' opinions: An information integration analysis. Bulletin of the Psychonomic Society, $1974 a, 3,44-46$.
Levin, 1. P. Averaging processes and intuitive statistical judgments. Organizational Behavior \& Human Performance, $1974 \mathrm{~b}$, in press.

Levin, I. P., \& Kaplan, M. F. The set-size effect in impression formation is not an artifact. Bulletin of the Psychonomic Society, 1974, 3, 187-188.

Levin, I. P., Schmidt, C. F., \& Norman, K. L. Person preference choices: Tests of a subtractive averaging model. Journal of Experimental Psychology, 1971, 90, 258-261.

Peterson, C. R., \& Beach, L. R. Man as an intuitive statistician. Psychological Bulletin, 1967, 68, 29-46.

Sloan, L. R.. \& Ostrom, T. M. Amount of information and interpersonal judgment. Journal of Personality \& Social Psychology, 1974, 29, 23-29.

Spencer, J. Estimating averages. Ergonomics, 1961, 4, 317-328. Spencer, J. A further study of estimating averages. Ergonomics, $1963,6,255-265$.

\section{NOTE}

1. In an unpublished study conducted in the writer's laboratory varying sample mean over the same range used in the present study but holding set size constant, the rating responses of each of $30 \mathrm{Ss}$ varied systematically as a function of sample mean. In the present case, the data of 8 of the 68 Ss failed to show a relationship between rating responses and mean percentage price increases. It was concluded that with the more complex instructions and materials used in the present case, these Ss apparently failed to understand the task. Consequently, their data were excluded from further analysis. It should be emphasized that the decision to exclude the data of a given $S$ was not based on consideration of the effect of the variable of major theoretical interest, set size.

(Received for publication March 18, 1974; revision received May 17, 1974.)

LOFTUS, E. F., WIKSTEN, S., and ABELSON, R.P. Memory \& Cognition, 1974, 2, 479-483. The title should read "Using semantic memory to find vs create a word," instead of "Using semantic memory to find vs create a mood." 